\title{
Self-Regulated Strategy Development in the Correctional Environment: A Research Proposal for Students with Comorbid Emotional/Behavioral Disorders and Learning Disabilities
}

\author{
Barbara Bari \\ Indiana University, United States of America
}

\begin{abstract}
The purpose of this study is to assess the effectiveness of the Self-Regulated Strategy Development (SRSD) model on both behavior and writing sills on three adolescent Caucasian and three African American male youths identified with comorbid learning disabilities (LDs) and emotional/behavioral disabilities (EBDs) in a correctional facility using a multiple baselineacross-participants design with multiple probes. While the SRSD model has been evaluated in public schools at both the elementary and secondary levels, thus far no research study has yet been conducted for youth in the correctional environment, and this is a population of students who are at greater risk of not succeeding in the general public workforce, and for whom recidivism rates are high [4]. This study extends the current research to include students in a corrections environment, and establishes a new focus on the effects the SRSD instruction has on student behavior.
\end{abstract}

\section{Introduction}

"Writing is the primary method by which students demonstrate academic knowledge and communicate with others" [7]. Writing proficiency, however, is no longer limited to the world of academia, but is instead becoming a day-to-day requirement in the average American workforce [1]. Studies now show that the majority of employers deem writing skills ability to be a crucial element that directly influences who they will hire and promote in the workplace [20]. However, studies have shown that teachers actually spend less time on writing skills than they do on any of the other academic core skills such as math or reading [1].

Writtten language competency is made up of acquisition, performance, and fluency in writing skills" [21]. In their 2007 high school report, the Institute of Education Sciences (IES) stated that $85 \%$ of the nation's $12^{\text {th }}$ grade, non-disabled students performed at or above the "basic" writing level, while only $44 \%$ of students with disabilities performed at this same level [11]. This means that
$56 \%$ of students with disabilities scored below the basic level for writing proficiency, and these are students with disabilities in the public school system. Youth in our nation's correctional systems suffer a far worse fate.

There are numerous reasons why this may be: Frequent absenteeism from school in the early learning years; lack of motivation for students to attend school; substandard learning conditions in the public schools; lack of student engagement in the lessons taught; numerous multicultural issues [22]; as well as numerous incarcerations which remove youth from the general education classroom.

Functional literacy deficiencies are quite possibly the strongest commonality aomong individuals in corrections [21]. While studies have shown that only $28 \%$ of incarcerated youth are reading within two grade levels below their actual grade level [21], [4], there is a relative lack of statistics concerning the writing abilities of these youth [21]. According to Baltodano, the only current available information on student writing statistics for incarcerated youth lies embedded within other studies of academic achievement of this population [2]. Foley estimates that nondisabled youth in our nation's juvenile correctional programs are achieving at the below average to average level of proficiency for writing skills, demonstrating significantly lower writing scores than their non-incarcerated peers [4]; while a study done by Lederman, 2004, indicates that incarcerated youth performed "poorly" on the written language component of standaqrdized tests, had more difficulty than their non-incarcerated peers in composition writing, and finally, performed poorly in skills such as sentence construction. Therefore it can be concluded, according to Lederman, that interventions focusing on written language competency as well as other academic skills are needed in order to decrease recidivism rates and increae employability of these youth [15].

It is estimated, however, that $40 \%$ of the youth found in correctional programs have some sort of a disability, the most prevalent being emotional/behavioral disorders (EBDs) and learning disabilities (LDs) [5]. The U.S. Department of Education reports that the 
prevalence of students with EBDs in the correctional setting is six times that of students with EBDs in public schools [2]. Therefore the prevalence of EBDs in the correctional environment is roughly $18 \%-36 \%$, when using the Kauffman estimate of prevalence of EBDs in schools of 3\%--6\% [12]. Reports also indicate that $60 \%$ of youth in incarcerated settings with emotional impairments have three or more comorbid disabilities [23], thus increasing the likelihood that these students will not succeed academically.

Studies highlighting the academic achievement of incarcerated youth with disabilities is very limited, yet it is imperative that students in the correctional setting receive a quality education with high standards for two reasons: (1) The education that they receive in the correctional setting may be their last opportunity to obtain an education [4], and (2) Writing proficiency is critical in the workplace" [1]. While this may be true, it is interesting to note that while very few teachers will question the value of teaching these students to write, very little actual time is being spent on actually teaching this skill [10], and what little attention is given to writing skills is done so under the guise of content-area or reading instruction [10].

Self-Regulated Strategy Development (SRSD) is an approach to the mechanics of writing that simultaneously serves as an intervention to improve the behavior of the writer [14]. The SRSD intervention strategy is utilized at the second tier of a traditional classroom-wide Response to Intervention (RTI) where interventions implemented at the first tier have been found to be ineffective [14]. There are three objectives in the SRSD process: (1) The mechanics of composition, (2) the development of knowledge and selfregulatory strategies, and (3) the increase in selfmotivation [14].

The SRSD method has been found to be effective with students in all grades, for students with and without disabilities, and for students with learning disabilities or learning disabilities coupled with emotional and behavioral disorders. Several studies have been done highlighting the effects of SRSD on normal elementary students [6], on students with EBDs in the elementary classroom, [19], [18], [17], and on students with EBDs comorbid with LDs in the elementary school classroom [14]. Replication studies have been perfomed with success at the elementary school level, which also extended the work of Graham and Harris, 2003, by performing the replication in conjunction with an existing PBS structure. The majority of the research has been performed on the elementary school population, presumably because this population is more responsive to treatment, and the studies stress the importance of treating students with EBDs and LDs early, before the child has reached a stage of resilience to treatment [16]. Several studies using the SRSD model for students having EBDs have been completed at the middle school [17], and high school levels — with one high school study replicating the original SRSD research model while generalizing it to the high school population for students also having learning disabilities [3], while another high school study focuses on SRSD for students with disabilities other than learning disabilities [24], and yet another high school study focuses on replicating SRSD on students in an EBD environment while investigating thte influence of peer groups on students.

To date, no studies have been completed for students in the correctional environment, and this is a population of students who are at greater risk of not succeeding in the general public workforce, and for whom recidivism rates are high [4].

\section{Purpose}

The purpose of this study is to replicate and extend the original work of Graham and Harris (2003) to include the high school correctional population, as well as replicate and extend the work of Lane (2008) which studies students with EBDs and LDs at the elementary level, as well as to establish a new focus on the effects the SRSD instructional model has on student behavior.

\section{Research Questions}

The following four research questions have been generated concerning youth in the high school corrections setting: (1) Is the SRSD writing model effective? (2) What EBDs are most responsive to the SRSD model? (3) What individual behaviors are affected by the SRSD model? (4) Is the anticipated behavior change generalizable to other academic settings?

\section{Method}

\subsection{Setting}

This study will take place at an alternative educational facility in the Midwestern United States. The facility is a maximum security, 84 bed institutions for adolescent males between the ages of 12 and 18 years that have been committed by the State Department of Correction.

\subsection{Participants}

Six male adolescent youth between the ages of 15 and 18, all matriculated in a tenth grade level language arts program will participate in the study. Ideally, 3 of these youth will be Caucasian and 3 African American. To be included in the study, the youth selected must meet the following criteria: (1) A diagnosis of a LD based upon their Individualized Educational Program (IEP), (2) the presence of a behavior disorder based upon the 
results of the Child Behavior Checklist (CBCL), (3) an IQ in the range of $80-115$ as evidenced by the Wechsler Intelligence Scale for ChildrenThird Edition) as taken from the student IEP, (4) achievement scores at least 2 years below grade level in writing as evidenced by the Wechsler Individual Achievement Test (WIAT) subtest of written expression, as taken from the student IEP, and (5) the absence of any other disabling condition. The only other criteria for participation is a $70 \%$ or better class attendance, written consent from the correctional facility for student participation in the study, parental or guardian consent, as well as student consent, [3].

\subsection{Variables}

The independent variable in this study is the SRSD writing model. The dependent variables are: externalizing behavior, essay length, essay quality, and basic story elements - all of which will be carefully and operationally defined.

\subsection{Instructional procedures}

Following the Chalk (2005) research study instructions, the principal author will provide the instructions for the intervention and will administer all of the writing probes in the language arts class. Scripted administration instructions will be given to the world history teacher to ensure that the procedures for essay writing will remain consistent across students and across the two content areas of language arts and world history.

The writing lessons will consist of five sessions, 25 minutes in length, within a 50 minute class period. Five lesson plans with check-off lists will be developed by the principal author to be distributed to the two language arts instructors with instructions that the lesson plans must be followed exactly as written, and each check-off list must be completed when administering the lesson to the class. All students are to be taught the same lesson, regardless of whether they are participating in the study. Before commencing instruction, the principal author will develop a list of 26 essay topics based upon the language arts teacher's instructional materials. The list of topics will be reviewed with the language arts teachers in order to assess their "appropriateness, interest level, and difficulty" for the targeted classes. [3]. Any topics found to be unsuitable for the class will be eliminated from use. A language arts instructor not connected with the study or with Indiana University will randomly select and pre-assign the essay topics that will be used as probes during the study. All remaining essay topics may be used during instruction as examples.

During each lesson, the following format will be used for student instruction: (1) Students will be given the following instructions to be followed exactly as written: "Please clear your desks except for two pieces of lined paper and a pencil" [3], (2) the essay topic will be read aloud to the students and clarification given when requested, (3) students will be given the following instructions "Based on the topic provided, you will have 15 minutes in which to write an essay", (4) teachers are instructed not to provide feedback or student assistance of any kind except to redirect student attention when he appears to be off task, and (5) verbal praise will be given after completion of the essay.

\subsection{Self-regulated strategy development}

Based upon the research completed by Chalk (2005), the following SRSD 6-step strategy will be used:

1. Step 1: Development of Background Knowledge. In this stage the focus will be on assisting students in the acquisition of the necessary skills before they learn the strategy. In order to achieve this, teachers will begin with activities aimed at teaching students to identify and create the basic parts of an essay. A chart with the mnemonic "DARE" will be introduced to the students as an assistive device for this activity. Dare stands for Develop the topic sentence, $\boldsymbol{A}$ dd the supporting detail, $\boldsymbol{R}$ eject arguments from the other side, and $\boldsymbol{E}$ nd with a conclusion. The teacher will go over each step in the "Dare" process with the entire class to augment student understanding of the process. Students will then pair up and practice reciting the "DARE" steps until each partner can recall the steps completely from memory. The teacher will then instruct the students on ways to generate details for a given topic, and practice recognizing and rejecting opposing arguments.

2. Step 2: Collaborative Conference. In this stage the teacher will review the baseline scores with each individual student for behavior, length of essay, and quality of essay using the aforementioned rubric. The teacher will also provide each student with a folder containing a table and a graph in which their baseline scores have been plotted and to which they will add each piece of probe data collected. The teacher will then collaborate with the student to set target goals and establish a criterion for meeting these goals for the student's writing as well as behavior. It is anticipated that all students will have a different set of goals and criterion as the students have entered the facility with varying abilities and skills acquisition. It is expected, however, that a minimum goal of a $25 \%$ increase in the number of words written, and a 2 point increase in quality score will be achieved by all students. At this time the teacher will also reiterate the importance of acquiring good writing skills as well as good behavior, not only in school performance but in one's career post-graduation. At this time the teacher will introduce the student to the following 3-step writing strategy: (1) Think-who is my audience and what is my paper trying to 
accomplish? (2) Plan-- what am I going to say using the DARE mnemonic? (3) Write, and write on! This strategy was developed initially to be used as a basic tool to assist students in organizing their paper, but was also developed to help students consider who will be reading their final product and their own purpose for the writing. As the teacher introduces the student to the 3-step strategy, he will also explain the importance of each step and inform the student that a poster containing the 3-step strategy would be posted on the chalkboard in the classroom during writing activities [3]. Finally, at the close of step 2, the instructor will ask the student to make a commitment to use the strategy in all of his writing endeavors.

3. Step 3: Strategy Modeling. This stage will commence with a review of the three-step strategy. Following, one of the essay topics will be read to the students. The teacher will then model the 3-step strategy using an overhead projector and a "think aloud" technique. [3]. With this think aloud strategy the teacher will commence writing the essay while constantly asking questions aloud to model for the students what they should be thinking and doing as they begin writing their of essays. At the end of this modeling step, the teacher will then introduce the concept of "selfinstruction" including a discussion of the "four main types of self-instruction" as suggested by Graham and Harris (1989): problem definition, planning, self-evaluation, and self-reinforcement [3].

4. Step 4: Strategy Memorization. During this phase, students will again be given time to practice memorizing the DARE strategy as well as the 3-step strategy in pairs. When the student thinks that he has mastered the steps, he will then create a visual aid for himself using markers and $5 \times 7$ inch index cards that he could keep in his writing progress folders. On the back of this index card the students will write examples for each of the steps that they may refer to later as they begin writing independently. Samples of examples for each of the steps could include (1) Problem Definition"What problem will this paper be solving?" (2) Planning-- "First, I will ......and then I will...." (3) Self-Evaluation-- "Did I do what I set out to do?" and (4) Self-Reinforcement-- "Fantastic-I came up with a really good set of reasons in this paper!" [3].

5. Step 5: Collaborative Practice. During this stage the student will use the visuals that have been previously provided in order to collaborate with the teacher, again using the overhead projector and the "think aloud" strategy. The teacher will be responsible for leading the instruction, but the student will be primarily responsible for providing the input for the body of the paper. Students in this phase will also be encouraged to use the selfinstruction procedures. During this stage the students are encouraged to go back and review the goals set for themselves during the collaborative conference.
6. Step 6: Independent Practice. In this final step, students will be expected to independently write two essays. The visual aids from the previous steps may be used in this step, but students should be encouraged to use them only in cases where every effort has been made by the student to complete the activity without them. Positive praise and feedback will be initially given, but will be faded gradually over time.

\subsection{Data collection}

Externalizing behavior will be defined as the presentation of any of the following actions during school hours as evidenced by the students' daily school behavior record: Use of profane language, throwing any object six inches or more away from the one's person, any demonstration of physical aggression against self and/or another individual, (to be defined as any violation of self or another person that elicits any of the following behaviors from the party offended: A negative verbal response, the rendering of self or another person unconscious and therefore unable to verbally respond, any physical violation of self or another person resulting in an open wound with blood present), any verbal threat issued against another individual or member of that individual's family, speaking without raising one's hand when one is not invited to do so by the instructor, and/or being out of one's seat when not authorized by the instructor to do so. The presence of these behaviors will be noted by personnel trained by the facility for the purpose of noting these behaviors. Inter-observer reliability for these trained individuals will be calculated by the principle author by dividing the number of agreements by the sum of agreements plus disagreements. In order to be acceptable, the reliability of both recorders of behavior must be $80 \%$ or better.

Student essay length can be defined as and will be measured by counting the number of words written in said essay. The total number of words or partial words, regardless of spelling correctness, will be counted. The essay length will first be calculated by one of the language arts instructors and then re-scored independently by the primary author, who will have the responsibility of training both of the two instructors in evaluating student essays using the rubric. Reliability will also be scored for each essay written. Reliability will be determined by dividing the number of agreements by the sum of agreements plus disagreements. In order to be acceptable, the reliability on the scoring of the length of the student essay must be above $80 \%$.

Basic story elements can be defined as the inclusion in an essay of the following elements: main character(s), locale, time, what the main character wants to accomplish, an action that will allow the character to achieve this goal, a description of the consequences of this action piece, and the characters' reactions. Each of these 
individual elements will receive a score of 1 if the element is present, and a score of 0 if the element is absent. These seven parts correspond to the seven elements that the language arts teacher will cover in her "pre-skills" lesson prior to the introduction of the intervention [14]. The elements will be scored by one of the two language arts teachers. Reliability will be determined by dividing the number of agreements by the sum of agreements plus disagreements. In order to be acceptable, the reliability on the scoring of the length of the student essay must be above $80 \%$.

Student essay quality can be defined as and will be measured by the lead author as well as the language arts instructor using the rubric established in the Chalk (2005) study. The rubric utilized evaluated four areas: Focus and development, organization, fluency, and conventions. The essays will be socred using a 6 point scale with a "1" representing the lowest quality of the essay and a " 6 " representing the highest quality essay. When the two instructors grade an essay with adjacent scores the average of the two scores will be used [3]. When the given scores are discrepant, a third trained instructor will be brought in to score the essay. The average of all three scores will be used as the final socre.

During writing probe administration the teacher will: (1) Clearly state the topic for the essay, and (2) provide the following instructions to be administered exactly as written: "Based on the topic provided, write an essay" [3]. The only other instruction that may be given is to redirect a students' attention when they appear to be off task, and no questions will be answered other than those requesting clarification of the topic. Teachers will be instructed not to provide spelling, punctuation, grammar assistance, or feedback of any kind. Students will be given 15 minutes in which to complete their essay, with the following 1 minute warning given after 14 minutes: "You have one minute left in which to complete your essay. Please complete any last thoughts or sentences at this time." At the 15 minute mark the teacher will respond with "Please place your pencils on your desks" [3].

\section{Validity}

\subsection{Social validity}

Social validity will be measured for both teachers and students during both the baseline and the postintervention phases using the Intervention Rating Profile (IRP), and the Children's Inervention Rating Profiole (CIRP).

\subsection{Instructional validity}

Instructional validity will be established by two means: (1) Teachers will be trained by the primary author on how to deliver the instruction and (2) they will use a checklist to ensure coverage of all components for which they were trained.

\section{Experimental Design}

This study will replicate and extend the work based on the SRSD model [3], [14], [10], with the addition of a behavior component.

The effects of this SRSD model will be assessed using multiple-baseline-acrossparticipants with multiple probes design including the following probes: (1) baseline, (2) pre-skill instruction, (3) modeling, (4) controlled practice, (5) independent practice, (6) post-instruction, (7) maintenance, and (8) generalization.

Data will be initially analyzed using visual inspection to examine stability, level, and trend [3], [14]. Repeated-measures of analysis of variance will be conducted with follow-up trend and pairwise comparisons to determine which conditions will be significantly affected over time [3]. Calculations of mean change and standard deviation for the number of words written, basic writing skills, quality of writing, and daily behavior within each condition. Performance on the behavior and social validity rating scales will be assessed as addressed in their respective administration manuals. All data will appear in a "Results" section of the final study write-up.

Once the data has been analyzed and reported, a discussion of the results, limitations of the study, direction for future research and a conclusion will appear in the "Discussion" section of the final study write-up.

\section{References}

[1] Baker, S.K., Chard, D.J., Ketterlin-Geller, L.R., Apichatabutra, C., \& Doabler, C. (2009).Teaching writing to at-risk students: The quality of evidence for self-regulated strategy development. Exceptional Children, 75(3), 303-318.

[2] Baltodano, H. M., Harris, P. J., \& Rutherford, R. B. (2005). Academic achievement in juvenile corrections: Examining the impact of age, ethnicity and disability. Education \& Treatment of Children, 28(4), 361-379.

[3] Chalk, J.C., Hagan-Burke, S., \& Burke, M.D. (2005). The effects of self-regulated strategy development on the writing process for high school students with learning disabilities. Learning Disability Quarterly, 28, 75-87.

[4] Foley, R. M. (2001). Academic characteristics of incarcerated youth and correctional educational programs: A literature review. Journal of Emotional and Behavioral Disorders, 9(4), 248-259.

[5] Gagnon, J.C., Barber, B.R., Van Loan, C.L., \& Leone, P.E. (2009). Juvenile correctional schools: Characteristics and approaches to curriculum. Education and Treatment of Children, 32, 673-696.

[6] Glaser, C., \& Brunstein, J.C. (2007). Improving 
fourth grade students' composition skills: Effects of strategy instruction and self-regulation procedures. Journal of Educational Psychology, 99(2), 297-310.

[7] Graham, S. (2006). Strategy instruction and the teaching of writing: A meta-analysis. In Lane, K.L., \& Menzies, H.M., (2010). Reading and writing interventions for students with and at risk for emotional and behavioral disorders: An introduction. Behavioral Disorders, 35(2), 82-85.

[8] Graham, S., Harris, K.R., \& Mason, L.H. (2003). Self-regulated strategy development in the classroom: Part of a balanced approach to writing instruction for students with disabilities. Focus on Exceptional Children, 35, 1-16.

[9] Graham, S., \& Harris, K.R., (2003). Students with learning disabilities and the process of writing: A metaanalysis of SRSD studies. In H.L. Swanson, K.R. Harris, \& S. Graham, (Eds.), Handbook of Learning Disabilities (pp. 323-344). New York: Guilford Press.

[10] Graham, S., \& Harris, K.R. (1997). It can be taught, but it does not develop naturally: Myths and realities in writing instruction. School Psychology Review, 26, 414424.

[11] Institute of Education Sciences. (2007). The Nation's Report Card: Writing 2007. Institute of Education Sciences, National Center for Education Statistics, U.S. Department of Education. Retrieved October 09, 2011,

fromhttp://nces.ed.gov/nationsreportcard/pdf/main2007/2 008468.pdf

[12] Kauffman, J.M. (2005). Characteristics of emotional and behavioral disorders of children and youth. Upper Saddle River, New Jersey: Pearson Education, Inc.

[13] Lane, K.L., \& Menzies, H.M. (2010). Reading and writing interventions for students with and at risk for emotional and behavioral disorders: An introduction. Behavioral Disorders, 35(2), 82-85.

[14] Lane, K.L., Harris, K.R., Graham, S., Weisenbach, J.L., Brindle, M., \& Morphy, P. (2008). The effects of self-regulated strategy development on the writing performance of second-grade students with behavioral and writing difficulties. The Journal of Special Education. 41(4), 234-253.

[15] Lederman, C.S., Dakof, G.A., Larrea, M.A., \& Li, H. (2004). Characteristics of adolescent females in juvenile detention. International Journal of Law and Psychiatry, 27(4), 321-337.

[16] Little, M.A., Lane, K.L., Harris, K.R., Graham, S., Story, M., \& Sandmel, K. (2010). Self-regulated strategies development for persuasive writing in tandem with schoolwide positive behavioral support: Effects for second-grade students with behavioral and writing difficulties. Behavioral Disorders, 35(2), 157-179.

[17] Mason, L.H., Kubina, R.M., Valasa, L.L., \& Cramer, A.M. (2010). Evaluating effective writing instruction for adolescent students in an emotional and behavioral support setting. Behavioral Disorders, 35(2), 140-156.
[18] Mason, L.H., \& Shriner, J.G. (2008). Self-regulated strategy development instruction for writing an opinion essay: Effects for six students with emotional/behavioral disorders. Reading and Writing, 21, 71-93.

[19] Mastropieri, M.A., Scruggs, T.E., Mills, S., Cirar, N.I., Cuenca-Sanchez, Y., Allen-Bronaugh, D., Thompson, C., Guckert, M., Regan, K. (2009). Persuading students with emotional disabilities to write fluently. Behavioral Disorders, 35(1), 19-40.

[20] National Commission on Writing (2004). Writing: A ticket to work...or a ticket out: A survey of business leaders. Retrieved October 09, 2011 from http://www.writingcommission.org/report/html.

[21] Rogers-Adkinson, D., Melloy, K., Stuart, S., Fletcher, L., \& Rinaldi, C. (2008). Reading and written language competency of incarcerated youth. Reading \& Writing Quarterly, 24(2), 197-218.

[22] Salinger, T. (2010). Meeting the literacy needs of students in juvenile justice facilities. Washington, DC: National Evaluation and Technical Assistance Center for Children and Youth Who Are Neglected, Delinquent, or At Risk (NDTAC).

[23] Shufelt, J, \& Cocozza, J. (2006). Youth with mental health disorders in the juvenile justice system: Results from a multi-state prevalence study. Retrieved October 09, 2011, from the National Center for Mental Health and Juvenile Justice website. http://www.ncmhjj.com/pdfs/publications/PrevalenceRP B.pdf

[24] Taft, R.J., \& Mason, L.H. (2011). Examining the effects of writing interventions: Highlighting results for students with primary disabilities other than learning disabilities. Remedial and Special Education, 32(5), 359-370.

[25] U.S. Department of Education (2009). 28th annual report to congress on the implementation of the Individuals with Disabilities Education Act. Retrieved October 09,

2011,fromhttp://www2.ed.gov/about/reports/annual/osep /2006/parts-b-c/index.html. 